\title{
MANUFACTURE OF ALKALIS AND ACIDS.
}

\author{
By WATSON SMITH, F.I.C., F.C.S.
}

Read Dfaember 14th, 1893.

\section{INTRODUCTORY.}

Having very much to crowd into this one lecture, I shall not waste your time or ald to my own embarrassment by commencing with anything worthy of the name of an introduction. As far as any further movement towards legislation is concerned in connection with the question of the hygiene of processes and occupations involved in the manufacture of alkalis and acids, since such manufacture consists of a series of chemical operations on a large scale, it was absolutely necessary in the first instance to make inquiry. But the recent inquiries at first instituted by our Government, as well as by certain of our newspaper commissioners, owing to the fact that scientific and expert knowledgre had been overlooked, only led to the raising of a general dust or fog. Only one instance is necessary to illustrate the depth and thickness of that fog, and as it is an instance both brief and amusing, I will give it you. During the Government inquiry in November of last year, a workman gave the alarming information that sometimes the Bleaching Powder Chambers were in a red hot condition when the packers were required to enter them. When I tell you that bleaching powder chambers are almost invariably macle of thin sheet lead supported by light woodwork, and that heat is the ruin of bleaching powder, that a red heat and bleaching powder-or even a bleaching powder chamber, are nearly as incompatible as a red heat and iced cream, you may imagine the wrong feeling or confusion such false statements would create. However, whether the trutl is finally arrived at by the process of reductio ad absurdum or direct reasoning, makes little matter so long as darkness or fog is at length dispelled and the light shines. When that desirable stage is at length arrived at, then we can all look back and smile at our errors and wanderings when in the dark.

Now on the subject of the physiological action of the materials, products, and surroundings of factories, especially chemical factories, on the workpeople, and the collection of accurate scientific evidence, I may tell you the Germans stand foremost, and therefore you will not be surprised that I quote largely from the observations of German authorities. Of the Alkalis we shall now consider, I shall begin with 
Ammonia, and it will be best under the head of ammonia to commence with its sulphate, the commercial Sulphate of Ammonia.

\section{Ammonia Industry.}

Sulphate of Ammonia.-In very many branches of chemical industry it has been found by the manufacturer that the method of working which is the most profitable and the most economical is the very one which also secures the healthiest conditions for the workpeople. Let us trace the collaterally improved economic and hygienic conditions of the process for manufacturing sulphate of ammonia since 1868 , and I will give you here the result of my own personal experience.

In 18 tiz sulphate of ammonia was made by heating in wroughtiron boilers or stills ordinary gas-water or tar-water from our gas works along with slaked lime, a pipe from the top of the still leading the gaseous ammonia into diluted sulphuric acid,

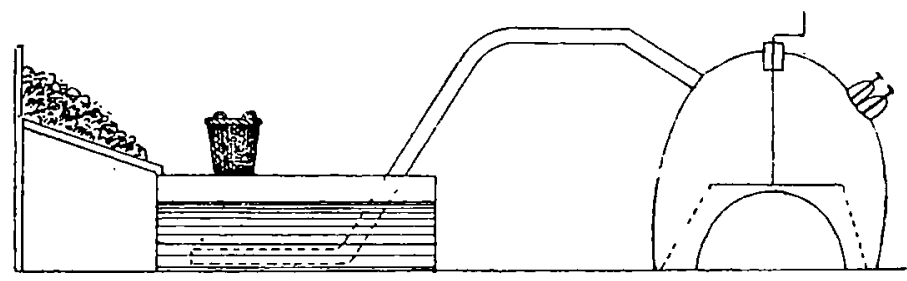

Original Sulphate Tank ( $18 \overline{5} \overline{7})$.

contained in an open cistern made of wood, lined internally with sheet-lead. Now tar-water, which by the way was once used as a remedy-perhajs I had better say was a nistrum-for a variety of ailments, and taken internally too, may be defined as a watery solution of a variety of ammonium salts, with a small quantity of coal-tar bases, and generally a little film of tar floating on the surface. Chief as to quantity among these ammonium salts, are the carbonate and sulphicle. On boiling with milk of lime, especially at first, along with free amnonia, a certain and a considerable quantity of carbonic acid and sulphuretted hydrogen escaped from the acid cistern. The ammonia was absorbed by the sulphuric acid, the vigorous action causing the mixture in the tank to get warm, whilst carbonic acid gas "Gassing" in and sulphuretted hydrogen passed off into the air. Sulphuretted 1868. hydrogen gas is one of those singular chemical substances which smells worse the more dilute it is, and hence, as you may imagine, it was a difficult thing for the manufacturer to keep out of "hot water" with his neighbours in those days. The factory workmen grenerally knew how to doduge the fumes, but new hands, or strangers, were occasionally overpowered and rendered unconscious, and I recollect on one occasion a plumber 
who endeavoured to repair the leaden sicle of one of the cisterns during a dinner hour, was found afterwards with his boy assistant lying quite dead by the side of the cistern. Some of you would no doubt like to ask if they would suffer any pain. Absolutely none, I reply; no more than you do in going to sleep. Men who had been "gassed" at the sulphate tank in those early days told me that if ultimately favoured with a choice of deaths, they wonld not fail to choose that by "gassing" at the sulphate cistern or tank, it was so uncommonly like being overcome by sleep. A man so partially "gassed" as to feel unconsciousness commencing to creep over him would of ten rum ten or twenty paces away before falling, and I never knew or heard of a case where such feeling of alarm had been occasioned as to cause a man to run away for fresh air, in which he did not ultimately fall, and lie unconscions for at least a brief period.

The remedy adopted in the tar distilleries in those clays was Rough renely to lay the man with his abdomen over an empty petroleum adopted. barrel, and one man taking his head, and another his heels, they would draw him backwards and forwards over the rolling barrel. This remedy, though rough, was by no means irrational; it was a mechanical process for at once expelling the irrespirable gases, and of restoring normal respiration, and was always effective, except in very bad cases. The after-effects of unconsciousness through this "gassing" simply lasted for the day or over-night; the man feeling, as he would put it, "rather light-headed" for a time. However odourless the carbonic acid might be, the sulphuretted hydrogen mingled with it, and "scenting" it, gave rise to much trouble and many fines for the manufacturer, who at length constructed another kind of sulphate cistern, in which was an arrangement for cutting off the noxious gases from the workmen and carrying then to a

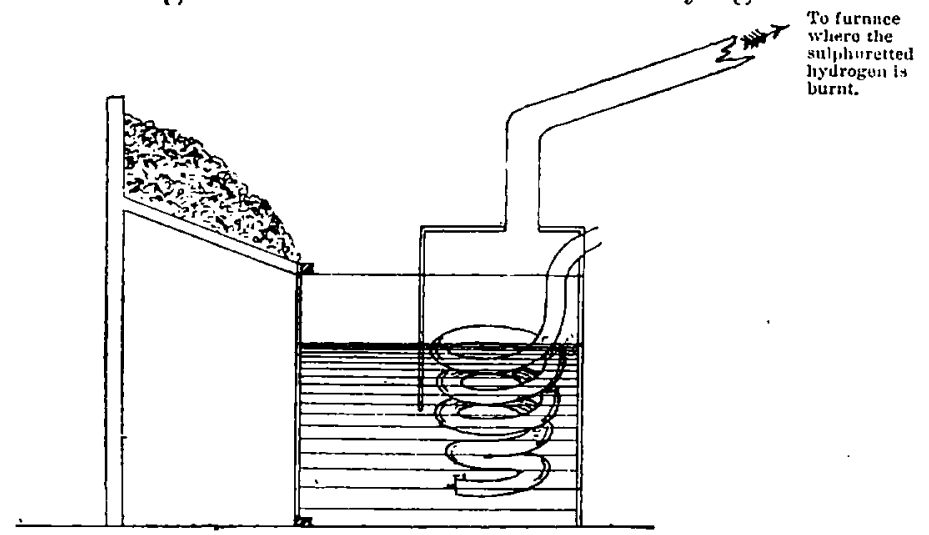

Improved Sulphate Tank (1872). 
(iovermment Inspection.

Present rundition. furnace flue, generally the steam boiler furnace. Thus, at all events, the workmen were spared; and I have seen this kind of sulphate cistern in full operation and the still too, under cover, and in the large room of an old cotton factory, in the north. However, the nuisance to the neighbourhood, though abated, still remained, and so the manufacturer's troubles, for sulphuretted hydrogen, mingled with so much carbonic acid, was apt to be carried away still to a considerable extent, unburnt.

Ultimately, the Govermment stepped in, and committed the matter to the care and supervision of the General Inspector of Alkali Works, and he now insists on the removal of sulphuretted hydrogen gas from the "sulphate gases" by means of an oxide of iron purifier, similar in principle to the oxide purifier employed in gas-works. In the meantime, the German Sulphate and Ammonia Manufacturers, Dr. Grïneberg, of Cologne, and Herr Feldmann devised improved stills, by which a certain proportion of ammonia, hitherto lost in the waste liquors and spent lime mud, was recovered, and these inventions far more than covered any expense incurred in the nuisance-abating purifiers, the use of which the Alkali Inspector had enforcecl. But a direct value arose in these purifiers for the manufacturer, for the oxide of iron therein in decomposing the sulphuretted hydrogen becomes itself converted into sulphide of iron, and this on roasting in suitable shelf-burners yields sulphurous acid, and in the leaden chambers, sulphuric acid, which can then be used over again in producing fresh sulphate of ammonia.

In England both the Simon-Grimeberg and the Feldmann stills are much used, as well as modifications of them.

At the present time, I consicler the hygiene of an ammonia and sulphate of ammonia works, under the supervision of the Alkali Inspector, is as perfect for the workpeople as ueed be. With regard to any injury or danger from ammoniacal gas (ammonia) itself, when we consider that the whole attention of the manufacturer is concentrated upon the most perfect condensation of the gas that is possible, and the most effective storage of the aqueous liquid, and that any annoyance to a workman's respiratory apparatus means loss of money to his master, you may imagine that the master's interests and the man's comfort in that respect coincicle witl most particular completeness. In short, workpeople in such a proprerly conducted works and with the best plant, are not exposed to any debilitating effects arising from small escapes of injurious gases or vapours.

Having said this of ammonia works, I may add that just the same remarks apply to the large factories where soda is manufactured by the Ammonia Soda process. 
I cannot close $\mathrm{my}$ account of the history of sulphate of Accident thro' ammonia making, without telling you a singrular accident which workent. occurred in 1870 in a works near Manchester, entirely owing to the neglect of a workman on the night shift. It had been thought in a still larger factory quite possible to distil the gasliquor and expel ammonia into the sulphuric acirl so as to form sulphate withont any addition of lime in the still. The smaller factory determined to stop the use of lime and follow the same course, and the night-men were warned not to neglect to keep the fires going regularly under the stills. During one evening, however, the attractions of a public house not far distant proved too much for the night workman, and lie left the premises and let the fire burn down under the one still he was in charge of. On his return that fire was nearly out and the pipes were cold. Alarmed at the result of his foolish neglect, he commenced to fire up vigorously. Now what haul occurred during the cooling process? At a given period, when ebullition was but feeble, a condensation of ammonium sesquicarbonate took place, vapours of that substance commencing to deposit in the pipes, eventually filling them and choking them up. On re-firing and re-starting the still then, that man was actually heating up a boiler absolutely closed and witl no pressure gauge! The final result was-naturally a terrible explosion which killed him and another man, and the rent still was carried up in the air over a row of cottages and deposited in a pond about 100 yards off. I may tell you that to dispense with the use of lime was not only a primitive process now never thought of, but a losing game for the manufacturer, since a careful analysis of the residual still-liquors would certainly have demonstrated the presence of an amount of ammonia that should never have been thrown away. Of course the apparatus used was of the primitive type I have already referred to. But the moral for many chemical factory men is as good to-clay, and as necessary, as then!

Ammonia.-In the manufacture of pure ammonia, or Liguor Ammonia, the health of the workmen is not affected at all, unless by such accidents as are analogous to a case say, like that of the fracture of the fly-wheel in the engine room of a large mill, such for example as the breaking of a carboy of strong ammonia and the accidental inhalation of its vapours. It is a case of loss to the master and pain to the man.

But let us now ask, "What is the physiological action of ammonia vapour?"

The investigations of Dr. Kar B. Lehmann, of Munich, on Physiological. this subject are most reliable. Those of Hirt seem on the antiononia. whole quite untrustworthy, so far as estimations of quantity, 
are concerned. Lelımann shows that there is extraordinary similarity in the action upon the respiratory apparatus of animals, between gaseous ammonia and gaseous hydrochloric acid. In experiments upon himself, this investigator exposed himself for half-an-hour in atmospheres containing $0 \cdot 20,0 \cdot 30$, and 0.33 per 1000 of ammonia, and two further experiments of twenty minutes each, in air containing 0.3 per 11100 . The following were the principal symptoms:-Respiration strongly nasal, slow and careful; rather strong stinging sensation in the nose, frequent sneezing. The deep inspirations by the mouth, excited during sneezing, caused some smarting in the trachea (windpipe). The eyes tingled so painfully that they could not be kept open, one after the other, long enough to read off a scale divided into half millimetres. Some lassitude and headache, the head becoming flushed, and perspiration excited, although the day was a cool one. Considerable secretion of saliva. Symptoms for the first five minutes especially unpleasant; however, gradually the experimenter grew somewhat inured to the effects. Nevertheless, the continuance in the room was attended with much discomfort, and though a further concentration appeared safe, yet it also seemed as if it would be unendurable. After leaving the room, the smarting in the nostrils and the headache continued for a time, gases were frequently got rid of by eructation, and then the normal conditions of bodily comfort returned. Another person in the room, with 0.3 per $1000(0.3 \%$ of ammonia, suffered in addition a slight pain in the breastbone, but ten minutes after leaving the room normal conditions returned. Still another person suffered neither the headache nor the sweating, and instead of sneezing, he complained of a painful feeling of swelling in the neck and throat, and also of feeling of great cold in one hand.

Now ammonia vapours are of ten pretty strong in the purifier house of our gas works, and Dr. Lehmann accordingly determined the amount of the volatile alkali present in the atmosphere of the purifier house of the Munich gas works, when the purifiers were being emptied. On one day the amount was $0.07 \%$, and on another when the odour was even stronger, $0.11 \% \%^{\circ}$. Such doses, he says, are on the verge of decided unpleasantness. However, it seems that larger quantities of ammonia than this were often present in the case of this gas works, for one of the workmen was suffering somewhat acute chronic conjunctivitis (inflammation of mucous membrane of the eye), or some ectropium (eversion of eyelids), the cause of which he attributed to his work.

Finally, Dr. Lehmann states it as his belief that with a little 
practice 0.3 to $0.5 \%$ of ammonia in the air can be borne a considerable time without sensible injury, and he is of the opinion that quantities of from 1 to 2 per 1000 can be endured for brief periods without injury. In any case, however, quantities over $0.5 \%$ in working spaces where men are confined for considerable periods, are decidedly to be condemned as injurious.

When Hirt therefore speaks of animals that have lived for a day in air containing $100 \%$ of ammonia and are none the worse, and of air containing $40 \%$ as being a respirable and the proper atmosphere to be artificially created for workpeople engaged in "silvering" mirror-glass to protect them from the mercury vapours, then I say such workpeople would be in the position of the proverbial fish in the frying-pan, with a protector who, to save them from the pan, suggests a jump into the fire! Lehmann says he knows indeed of no reliable investigation or data to show that the pouring of liquor ammonice on the floor of the mercurialising rooms of mirror factories is of actual benefit, but it appears to him actually ludicrous that Hirt should give a solemn warning against tincturing the atmosphere of such rooms with more than 4 to 5 per cent. of ammonia! (Hirt, Gewerbekrankheiten, Handb. der Hyg., Bd. 2, Abth. 4, page 28.)

Lehmann gives some very valuable experiences of chief engineer, Herr Pitzner, formerly a colleague of Prof. Linde, whose ammonia ice-machine is so well known. In bringing this machine to perfection, Linde with Pitzner were engaged for nearly three years, and through faulty stulfing-boxes, \&c., and various needs for repairs in the more primitire apparatus, considerable escapes of concentrated ammoniacal vapours took place. No real or lasting injury was ever noticed, and during Pitzner's eleven year's' experience with ammonia ice-machines, he never knew of a single death taking place that could be recorded as caused by the action of ammonia. When working with the incomplete machines the workmen were often ailing, but almost invariably with transitory ailments-bronchitis, conjunctivital catarrhs, \&c. Of chronic complaints traceable to ammonia vapours, Lehmann could find none; the catarrhs were mostly not of chronic character. Two workmen engaged as above he did not examine. They had been in the business many years, and were perfectly sound and healthy.

Pitzner himself often worked in rooms which he was compelled to leave every half minute or so for fresh air. $\mathrm{He}$ suffered from. no eye troubles. It seems that nature has provided for sucli dangers in the case of the eye, for so plentiful is the secretion of tears, that the cornea is preserved thus 
from attack. Another observation as to the action during brief periods of strong ammonia vapours is of interest, it is that a tendency to romit always arises, and sometimes actual vomiting takes place.

Of course now, either in the construction or use of icemachinery of the kind referred to, scarcely a trace of ammonia is perceptible, so perfect are the adjustments. For the medical expert it is, however, useful to know what the essential tendency of strong ammoniacal vapours absorbed internally, is. It is this : To attack and destroy the more delicate portions of the epithelium, laying bare places in which at once inflammation is set up. The curious thing is, that placed in contact with concentrated ammoniacal fumes, another service of nature prevents such fumes reaching the lungs, a cramp or stricture of the epiglottis taking place. On several experiments by Lehmann, the trachea and even stomach had become inflamed, whilst the lungs had remained intact.

An interesting, although a painful case, of choking with ammonia, and almost to the death, came under my notice in 1867. A boy, who had brought a sample into the laboratory of the works where I was then engaged as chemist, took up a bealier glass half-full of the strongest ammonia, and, thinking it was water, flung the contents full in the face of my laboratory boy and ran out of the room. I entered the room as the first boy left it. My laboratory boy was evidently in a paroxysm of distress; some of the ammonia had entered his mouth, and some his nostrils. He advanced towards me like one in a semicataleptic state, the back was umaturally bent inwards and the abdomen outwards; also owing to a cramp-like contortion of the legs and ankles, he seemed to stagger along on the toes alone. He raised his hands to my face, as I thought to scratch me, but his fingers were bent and cramped, and scratching was ont of the question. After this he seemed to sink into himself and collapse, falling to the ground. Of course we sent for a doctor, and did all we could for the lad. I observed no tendency to vomit, but when on the ground, he commenced a singular gyration of himself whilst lying on his side, by the action of his legs and feet. Now it is a singular thing that Lehmann observed just the kind of symptoms I have described, in the case of small animals he had subjected to the action of rather large quantities of gaseous ammonia. Especially the gyratory motion he specifies as characteristic of ammonia. The lad I have referred to lapsed into a comatose state, and was found pulseless by the doctor. Whilst apparently strong cerebral action had been set up, he had also choked through stricture of the epiglottis, which had closed and protected his 
lungs. The doctor administered a mixture of warm milk and alcohol, and in an hour the boy was restored to conscionsness. He complained of sore mouth and throat, but after lying-up for a few days with a kind of slight bronchial catarrh, he returned to work apparently none the worse for his adventure.

Turning to our great Ámmonia-Soda factories, let me remind Ammonia Soda you that all the movements of skilled engineering employed there, are in the direction of exclusion of the workman from any but traces of ammoniacal gas, for ammonia in that process is looked upon as we regard money stored in a mercantile concern and producing a given rate of interest upon which interest the investors are living. To let ammonia leak away or get lost during its circulation, would be like letting some of the capital sums invested dribble away. The whole genius of the ammonia-soda process is to continually circulate the same ammonia, or as nearly so as possible, and not lose it by leakages, \&c. I think I may safely predict that no reason or cause will ever arise for inspecting works and factories for the sake of preventing injurious escapes of ammonia.

Soda $A$ sh.-Whilst upon the subject of ammonia, and before sodr ash. concluding it, with also the ammonia-soda industry, I should like to say that there is nothing in this latter inclustry that I call injurious or clangerous, in the sanitary sense, in any properly conducted works. Of course, with soda ash, the crude carbonate, which, by the way, in the case of the ammoniasoda process, possesses very little if any crudity - the dust of the ash in packing is no rloubt irritating. The irritation is chiefly to the nostrils, and violent sneezing is inducell. This result alone is sufficient to compel the workmen to mutfle their mouths and nostrils, and in the case of a well defined dust, there is no difficulty then in aroiding the introduction of soda rlust into the moutli or throat. I have never known any injury to health to arise in the case of packing ash, even finely ground ash; a man is compelled to muffle up and protect his respiratory apparatus, by reason of the inordinate fits of sneezing induced if any attempt were made to dispense with them. I think we may say that the very solubility and immediate acridity of the fine particles of soda ash, form the best means of protecting the men who handle it from injury to their respiratory organs.

Canstic Soda. - This is the hydrate or hydroxide of sodium, Caustic solde and is obtained on the large scale by boiling the dilute solution of the carbonate with slaked lime, which, possessing greater affinity for the carbonic acid of the carbonate of soda than the soda has, appropriates that carbonic acid, leaving in solution the hydrate or caustic, the insoluble carbonate of lime settling down, and leaving as a clear liquid the dilute caustic, which is 
eventually evaporated down, at increasing heats, until it is brought to igneous fusion. With regarl to sanitation, caustic making is as healthy a process from beginning to end as soap boiling or brewing. I will tell you the only accident that ever came under my experience. When the prices of alkali reached a very high figure in 1873, some persons sold up their own businesses, and launched into small concerns for soda making, though without any knowledge of the subject, still less of the elements of chemical science. One such person, whom I assisted chemically for a brief period, set his caustic pots almost quite level with the platform on which the men stood, and insisted on their commencing work without supplying proper lights for the sheds at night. At last one man dipped his foot into strong, lot liquor, and was taken home with a bad burn; tetanus set in after about a week, and the man died. But your see I am only telling you here what might occasionally happen in the case of badly or insufficiently arranged plant, in the way of accident. However, there is no clanger now, or probably ever will be again, of alkali prices being such as to tempt strangers to go into the Leblanc alkali manufacture! I shall, therefore, venture to place the simple manufacture of solia ash and caustic, as regards sanitation, on a par with soap making, and indeed, soap manufacturers largely use botli sola ash and solid caustic.

Soder or Soda-or Alkali-Wuste, and the Recovery of Sulphur therefrom.-In older times, the alkali waste (an insoluble sulphide of calcium, mingled with a little carbonate of lime, cinclers, etc.) was thrown out upon waste land, and beaten down as closely as possible. It thus gradually suffered an oxidation process, which resulted in the evolution of sulphuretted hydrogen in the neighbourhood, which meant two things: the loss of the sulphur to the manufacturers, and a nuisance, in the shape of ill odours, to the neighbourhnod. However, I must deny that even this state of things affected appreciably the health of workpeople, for I can in this matter talk about my own health, after living and working for some six years in the thick of the vapours of Runcorn and Widnes, in Lancashire, and I simply say that my health was in every particular as good then as it is now that I am living in Hampstead. I do not deny, however, that a stranger coming, say from Hampstead, and pitching his tent in Widnes or Runcorn, or similar neighbouxhoods, for the first time, would suffer some nansea, and thus encounter what is described as a general "lowering of the system;" but I do say, that after a short time people become inured, and get the nervous system, shall I say " attuned," to these odorous conditions. In this connection I will indeed add 
my own personal confirmation to the statements of $\mathrm{Mr}$. Cooper, of Widnes, Dr. Ballard, the Alkali Inspector, Dr. Robinson and Dr. Monritz, of Runcorn, as given by Dr. .T. T. Arlidge in his work on "The Diseases of Occupution," pages 497-498; that, except to workpeople alreacly suffering from lung troubles, the vapours show no ill effects, not even in the intensification of maladies. However, a great revolution has been effected since then, in the introduction of a process for recovering the sulphur from alkali waste, known as the Chance-Claus process. By this Recovery or sulprocess the waste is mixed with water, brought to the state of phur from soin a cream, and then treated witl carbonic acid gas from limekilns, so as to set free the sulphuretted lyydrogen gas, which is subsequently half-burnt in an ingenious manner, and in an ingeniously contrived kiln, so that whereas in the ordinary way of burning in the air, $\mathrm{H}_{2} \mathrm{~S}+3 \mathrm{O}=\mathrm{H}_{2} \mathrm{O}+\mathrm{SO}_{2}$, in this case $\mathrm{H}_{2} \mathrm{~S}+\mathrm{O}^{2}$ only gives $\mathrm{H}_{2} \mathrm{O}$, and $\mathrm{S}$ is lett, and this sulphur is then deposited in a suitable chamber, collected and sold or used as brimstone, or the $\mathrm{H}_{2} \mathrm{~S}$ can be burnt, and the $\mathrm{SO}_{2}$ passed into the sulphuric acid chamber, to make sulphuric acid or vitriol.

At first, however, nuisances were caused by the new process, The Chancewhich had not been thoroughly brought under control. In the Government Alkali Inspector's Report of the year 1889, he confessed that "While the public and the Inspectors under the Alkali Act may be congratulated on the partial removal of one source of nuisance by the application of the Chance-Claus process, unfortunately that process itself in liable to be the source of a similar evil."

This was for 1889 , and since then, through the unflagging efforts of the maunfacturers, notably of $\mathrm{Mr}$. A. M. Chance, the inventor, and the friendly criticism of the Inspectors, so much improvement has been wrought, that in the last report of Mr. Fletcher, the Chief Inspector, dated 1893, he states: s' There was great difficulty, 'at first,' in preventing the escape of sulphuretted hydrogen, and for about six months before the uninor difficulties were overcome, much nuisance was occasioned near the works. This is now, however, passed, and the presence of that noxious gas is no longer perceived. The points of danger are now well understood and carefully watched." The last time I was in Widnes and was shown over a Chance-Claus plant there, I could perceive no odour of sulphuretted hydrogen whatever about it. If any friend from Widnes, or Runcorn, or St. Helens, be present, he may ask, "Then, why do we yet perceive occasionally odours of sulphuretted hydrogen on arriving at those towns"? I reply, those odours are from the old heaps of waste of years ago, in which the oxidation is not yet complete. 
Physiologicnl uction of sulphuretted liydro-
phuren gen.
Howerer, now we hare reached the subject of sulphuretted hydrogen, let me tell you something of the physiological results obtained by Dr. Lehmann, of Munich. He says (Arch. Hyg. $14,135)$, as the results of his experiments on the Toxic action of sulphuretted hydrogen, lie concludes to set 0.5 to 0.8 per million as the limit which must be drawn concerning an atmosphere, the remaining for a few hours in which begins to threaten some danger of injury to health. An amount of 0.15 per million of air appears, even after many hours' duration, not to. effect such damage, but from 0.2 per million clown to 0.15 is. sufficient after some hours, to produce unfavourable symptoms. To give you an idea what these figures mean, let me say that if you go now to Widnes or St. Helens, choose the most fragrant waste heap to be found, set up a tent upon it on a damp still day, when the fragrance is greatest, and after closing the tent door you test the air of the enclosed space, you will not find anything appronching Lehmann's minimum figure, viz., 0.15 permillion of sulphuretted hydrogen. Lehmann's figures will no. doubt be very useful to Medical Officers and to our Inspectors of Works.

How alliali men have sometimes cooked theit food
Use or custom is said to be "second nature," and I may tell rou I have secn workmen cook a chop and boil up their tea by scooping a hole in the side of a waste heap partly on fire, until a red-hot portion was reached. The food was placed on a clean spade and the latter pushed into the hole and kept there till the chop, was grilled and the tea boiled. The hole thus. served as an oven, and spite of a slight odour of sulphurons acid and a tincture of sulphuretted lyydrogen, chop and tea respectively, were at length eaten and drunk with appetite and relish.

\section{Sulphurous Acrd.}

This gaseous substance (sulphur dioxide, popularly known as "fumes of burning sulphur") is principally employed for" manufacturing sulphuric acid or vitrol. It is also used in bleaching wool, silk, and straw, and in the sulphite wood-pul p $^{\prime}$ process. It is produced in the purest condition by allowing sulphur to burn in the air in suitable kilns, the oxygen of the air supplied by a slow draught, combining with the sulphur. during combustion to evolve sulphur dioxide. A cheaper source of this gas is iron pyrites, the bisulphide of iron, which easily parts with one-half of its sulphur, and at a red heat and in presence of the oxygen of a sufficient supply of air, with the final half as well, and leaving oxide of iron (ferric oxide). If the iron pyrites be of a cupreous nature, so much the better for the manufacturer, as the copper left with the oxide of iron is easily extracted in a subsequent process by roasting the ground 
ore with common salt at a dull red heat, and then lixiviating the cooled charge in vats, with water and dilute hydrochloric acil. The green copper liquors are treated with scrap iron in separate precipitating vats, when the iron dissolves and the copper is precipitated as a metallic powder to take its place.

In making sulphuric acid, the kilns, whether brimstone kilns aranufacture of or pyrites lilins, are so arranged that their flame or lot gas passes through an additional kiln in which are cast-iron pots containing nitrate of socla, or Chili saltpetre, mixed with sulphuric acid, which must be in slight excess. The heat causes nitric acid to be driven off, which the sulphuric acid has alrearly set free from the nitrate of soda, and its vapours mingling with those of the sulphurous acid not only assist the oxygen of the air in oxidising this sulphurous acid to sulphuric acid or vitriol, but convert that oxidising process, otherwise a very slow one into a quicker, and also into a continuous process. Still the process is a comparatively slow one, and hence large spaces are required to accommodate such immense volumes of gas, and for this purpose large oblong chambers are built of light roodwork and lined internally with sheet lead, which dips into a hottom constructed like a huge dish of stronger sheet lead, so that the whole is something like a large tea-cup inverted in its sancer, but prevented by outer supports from resting its weight and mass quite on the bottom of that saucer, or like a huge oblong shaped gasometer which does not rise and sink, but is always as high up as possible. You will say, "yes, but the gasometer is luted at the bottom in water." I say, "just so," and the sides of the Vitriol chamber also dip into vitriol always present at a sufficient depth in the dished bottom so as to lute the bottom of the "curtain" of lead, as it is called. Just at the place where the sulphurous and nitrous acids enter the chamber, stean is also turned in. Inside those chambers a shower of rain is always falling upon the bottom and running down the sides, and that rain is sulphuric acid-it is a vitriolic shower. At the end of the chamber system is a leaden tower called the Gay Lussac Tower, the purpose of which is to catch and retain the costly nitrous fumes-a red choking vapour which would certainly injure health, but which the manufacturer has no intention whittever of allowing to escape. Gay Lussac discovered that cold strong vitriol easily dissolves nitrous fumes (nitrogen trioxide), and from this discovery arose the device called the Gay Lussac Tower. It is packed with hard cokes, and downwards from a cistern above, strong sulphuric acid trickles in all directions. This shower meets the ascending gases from the last of the system of sulphuric acid chambers, and absorbs all the nitrous fumes from them. Strong vitriol thus charged with 
Bygienic conditions.

Dangers in cleaning cham. bers and Ging Iussate Towers

nitrous fumes really forms a compound called nitro-sulphonic acid, which is easily dccomposed by water or dilute vitrol, especially if hot, the red nitrous fumes being set free for use over again. Now this description, though incomplete, will suffice for my purpose.

We have brought together in this remarkable process several acids and acid vapours, and so we will study their lyggienic bearing on the workpeople togetler. Do not think that sulphuric acid is only made by the Leblanc Alkali manufacturer, manure manufacturers, tar distillers, dye and colour makers, indeed all who want much sulphuric acid, often make it for themselves.

The question to which I now hasten is this: Is the manufacture of sulphuric acid injurious to the health of the workmen engaged? I answer without hesitation, " $N^{\top}$, it is not." It is not the object of the manufacturer to build expensive plant to generate gases and vapours, afterwards to be wasted by leakage into the air, a proceeding which, besides loss of money, would mean stoppage of his process by the Alkali Inspector, with a probable fine on a repetition; but it is his object to manufacture sulphuric acid, and so to confine and utilise to the utmost those noxious vapours engaged in its formation. The small quantities of sulphurous acid you may sometimes smell in Vitriol works are distinctly not injurious; that I say after a twelve year's' experience in such factories. But there are special occasions, which however only rarely occur, when great care is necessary, and when the men perhaps need some authoritative protection from their own ignorance and often downright obstinacy. Such occasions are the cleaning out of the chambers, or of a Gay Lussac Tower.

Let me say, at once, that when accidents occur through inspiring too much of the gases left in a chamber or a Gay Lussac Tower, to be cleaned out, the first cause is generally attributable to men entering too soon. But the second cause is not usually the sulphurous acid vapours present, but the residual nitrous fumes, and I think I camnot do better than direct attention to this fact. There is a number of noxious gases, all of which, if not too largely almixed with air, at once make you aware of the peril of your position in respiring them by certain unpleasant symptoms, but nitrous fumes form a notable and an insidious exception. Hence, even in the admirable book of Dr. Arlidge, I notice that the occasional accidents occurring on cleaning out the chambers, are evidently attributed to the sulphurous acid present. No doubt, as to odour, the sulphurous acid completely masks the much smaller quantities of nitrous gases, but there lies the danger. 
To convince you, in the first instance, that sulphurous fumes, of course in very small proportion, are by no means so insidious or injurious as they lave sometimes been represented, I would merely remind you that in times of cholera and other epidemics, you may expect, if neecl be, to be disinfected with burning sulphur fumes, which are sulphurous acicl, and that sulphurous acid in a liquid form, and in the form of bisulphites, forms a most valuable antiseptic and disinfectant. But I will give you also the results of the experiments of German investicrators, and especially of Ogata. Ogata, with several others, found Phrsiologicnt that 0.5 to 0.7 parts of sulphiurous acid, per 1000 of air, act phurous atid. seriously upon small animals, such as rabbits and guinea-pigs, in two hours inclucing incipient destruction of the cornea, bleeding of the lungs, emphysema (distension of tissues with gases), \&c., 2 to 3 per cent. sufficing to kill the animals in a few hours. Lehmann draws attention to the fact that Hirt's figures for sulphurous acid are 150 to 200 times higher than these, and since Hirt is an authority known in Englanrl as well as Germany, I beg to warn sanitarians that, whilst symptomatically Hirt is no doubt correct, Lehmann shows that most of his figures are terribly in excess of the truth.

This simply means that a totally irrespirable atmosphere is sometimes put down by Hirt as one that a man might safely pass a day in! But an atmosphere anywhere in a sulphuric acid works, which contains $0 \cdot 5$ part per 1,000 of $\mathrm{SO}_{2}$, could never be found under normal circumstances.

It may be interesting to know that the atmosphere of the Snlyhurous acic Metropolitan Uuderoround Railway tumnel at Gower Street is in Undergreunch sufficiently charged with sulphurous acid to make that tumnel act ${ }^{\text {at Gower }}$ Strees something like a sulphuric acicl chamber. Droppings from the roof which taste acid are continually falling on to the platform, which is whitened and corrorled by the weak vitriol, which these droppings certainly consist of. If you ask me as to injury to health caused by such an atmosphere, I say at once I don't belicve there is the slightent, except in the case of delicate or diseased lungs. I don't know what escape there is from the conclusion thint that tunnel is efficiently and cheaply disinfected against cholera and influenza, though "I certainly deprecate the presence of the solid particles of carbon of the smoke and any. carbonic oxide of the fuel gases.

But I spoke of the insidions nature of the mixed sulphurous Gases of elram. acid and nitrous vapours of the Vitriol Chambers and Gay Lussac Tower. This character is almost entirely due to the nitrous vapours. In the Chemische Industrie, 1854, p. 317, there is reference to a workman who died after cleaning ont a Chamber through the nitrous fumes, but a post-mortem proved that he had 
a rery diseased heart. A case is also given in the Chem. Ind., 1892, p. 284 , of the death of a man who had assisted in cleaning out a Gay Lussac Tower in which stoppages of draught had occurred. Although the tower had been, as was thought, thoroughly freed from acid and nitrous vapours by washing out with hot water, rumning down soda solutions and several days' airing, and the workmen, previous to their descent into the tower, had bound wet sponges over their mouths to act as respirators, nevertheless, one of the men, known as a sickly and weak man, was soon so affected by the dilute nitrous vapours, that after walking about a mile of his journey home he could go no further, and he died before the following morning. Yet the other workmen of stronger build lad worked for hours in the same atmosphere without apparently any injury whatever. In such cases it is recommended that special respirators should be furnished, with tubes, and a supply of air from outside. The best form of respirator for such a purpose as recommended by German authorities is that of König, known as the Patent Respiration Apparatus, to be obtained from Gustav Kleemann, Engineer, of Hamburg.

Nitrous fumes form an insidiously noxious gas, and I must explain what this means. If a wolkman, or even a chemist, unaccustomed to its mode of action, try to judge of the influence of air mixed with a small proportion of it upon their respiratory organs, by closely observing low they feel whilst respiring such atmosphere for a short time, they may find themselves woef ully deceived. To put it briefly, one of the principal symptoms, and that most characteristic of nitrous fumes, is the peculiarly deferred but alarming dyspnoa that after a time sets in. But, it is dyspnoea of a special order, for whilst the inspirations are comparatively unimpeded, the expirations become more and more difficult and painful.

You will be astonished when I tell you howerer that the rapours of nitric acid, like those of hydrochloric and sulphurous acid, are not to be compared with those of nitrogen trioxide (red nitrous fumes) for danger, nor is that danger to be found except very seldom in either alkali works or nitric acid factories. There is a case given in a German report from the Chem. Ind. 1892 , p. 283 , and it is typical of perhaps the only kind of serious occurrence in our modern nitric acid works. A workman who nitric acio worls liad the job of filling a pressure-cistern in the open air with an acid for nitrations, upset the vessel he was carrying, and apparently fearing a severe reprimand, he endeavoured to remove the spilled acid by washing it away with water, without saying anything about the mishap. He trusted that the vapours in the open air would become so quickly diffused as to 
become uninjurious. Such an acid would, however, generate volumes of nitrous fumes in contact with all organic matter it came in contact with. The man died in nineteen days after, from the effect of the fumes. For this class of work and sucli emer(rencies, that factory had respirators for the men, but what could a firm do in such a case as this?

Before leaving the subject of Sulphuric acid manufacture and vitriol chamber gomg on to Nitric acid manufacture, towards which I have been steadily advancing, let me say a word about the Vitriol chamber plumber. Dr. Ailidge in his work, page 463, says, "The evils of leatl are more severely felt by the plumbers, who tind constant work in making and repairing pipes, funnels, and chambers, and are exposed to the fumes of the solder they use as well as to the metallic lead itself." But the use of soft solder for cementing sheet lead is out of date, and plumbers now always use strips of soft lead, which metal is used with a blow-pipe flame, somewhat as sealing-wax is in sealing a parcel. I clo certainly not believe the plumbers suffer so much from lead fumes, for they need no such high temperature for their process as would cause appreciable lead fume, but they will use in their hydrogen gasgenerators exceedingly impure spelter, and impure sulphuric iciol, and both of these containing arsenic, they thus obtain lyvirogen in their blow-pipe apparatus, containing considerable quantities of arseniuretted hydrogen, which must be injurious. I have myself pointed the false economy of this to them, but plumbers are rather difficult persons to convince of the errors of their ways.

In conclusion of this subject of sulphuric acid manufacture German rules in I have just learnt that the German Government has issued cleuning Gasy certain directions or prescriptions with respect to the discharge or clearance out of the packing of Gay Lussac Towers in sulphuric acid works in Germany. The document is headed, "Besondere Cinfallverhïtungsvorschriften fïr das Auspacken ron Gay Lussac Thuïmen." These clirections are recognised and passed by the Imperial Insurance ()ffice, and were printed in the Reichscunzeiger, of 27 th November last. Let me say that the German Chemical Industries are represented in Berlin by special committees, and I understand that any regulations proposed by the Inperial Govermment are submitted to these committees before being passed, and once passed they have to be adhered to. Thus the manufacturers practically control, to a great extent, and under a wise Government supervision, their own affairs, and those matters relating to the health of their workpeople. I will now give you the recent German rules with regard to the Gay Lussac Towers. 


\section{A. Precautions and Directions roli tile Employer OF LABOUR.}

1. Before beginning to clear out the towers (Gay Lussac), which must only be done under supervision, every connection of the Gay Lussac Column with the chambers and other apparatus, must be cut off.

2. The Gay Lussac Tower still connected either directly with the chimney, or indirectly through the medium of an intervening Gay Lussac Tower, so that the through-dlaught is maintained, is now washed out, first with sulphuric acid and then with water or steam, until the exit washings only show a specific gravity of $3^{\circ}$ Baumé.

3. After this washing-out, the connection with any intervening Gay Lussac and the chimmey must be cut off, and the Gay Lussac to be cleared out must be closed up gas-tight. Then, where it is possible, a connection of the Gay Lussac with a chimney or a mechanical ventilator is made, and is maintained throughout the operation of clearing. If the tower is to be emptied from below, then exhaustion from above, with closed cover, is to be effected; if from above by descent into the tower, then exhaustion from below must take place. In the latter case the cover of the tower must be removed. If exhaustion be impossible, the cover should be removed and one large hole should be made below. Only after the tower is sufficiently freed from noxious gases should the clearing out of the packingr materials commence.

4. Towers packed with coke, or similar material, should be cleared out from the outside. In the case of high towers, or towers with several internal arches, arched supports, or gratings, several holes at various altitudes in vertical line from above downwards, should be made following the progress of the work, or the emptying process is to be effected step by step (" etagenweise"). Stone, or such like packings, are to be removed by the workmen by passing them out by hand, or hoisting them out by suitable winding-gear. All the packing material is at once to be carried out of the building, i.e., out of the neightbourhood of the Gay Lussac Tower. The workmen should, according to necessity, or, at all events, expressed desire, be at. once absolved from further continuance in the work.

5. The workmen should be supplied with good mouth sponges (as respirators), respirators, and proper coverings for their hands, such as india rubber gloves, hand wraps, \&c.

6. Before getting out the mud accumulated at the bottom of the Gay Lussac, water should again be caused to play upon it and be stirred well up anonest it from outside. If nitrous 
fumes arise, the liquid must be removed from outside, and the stirring up with water continued.

7. Workmen known to be affected with lung or heart affections, ought not to be employed in any of this clearing-out process.

8. Every manufacturer is directed to make known these "Measures of precaution against Accidents" (Unfallverhütungsvorschriften), by a printed notice set up in a suitable place in the factory. Besides this, these precautions must be impressed upon the workmen, and the dangers of the work be made clear to them, before they commence operations.

\section{B. Precautions and Directions for the Wormilen.}

9. If, during the clearing out process by entering the tower from above, and thus operating, nitrous vapours in large quantity are generated, the workman must at once leave the tower and acquaint his overseer or superior with the fact.

10. Workmen affected in heart or lungs, who are employed for cleaning out Gay Lussac Towers, are bound to communicate such fact to their overseer.

\section{C.}

11. Here follow a few penalties, the proceeds of which go to the Workmen's Sick Fund, in case of disregard of the rules prescribed as above. A member of the Society has to pay double subscriptions for his omission, whilst an insured person pays, for each offence, some penalty not exceeding $6 \mathrm{M}$ (six shillings).

As I have already said, during all my entire connection with Probable effect alkali and sulphuric works, I do not remember a single fatal of stringent miliaccident in clearing out chambers or Gay Lussac Towers, on chemical through inhalation of nitrous fumes. We must also observe that all the men in Germany, workmen and others, are soldiers, and the workmen class are those who will have a lively recollection of the "Unteroffizier," or otherwise of the stringent military" discipline conveyed in that single word, unquestioning instant obedience demanded, \&c., \&c., and it may be that such workmen have been ordered heretofore to clean towers and chambers by foremen still mindful of the office of Unteroffizier, and the men without word or question, have exposed themselves to the gravest perils, which in English factories could not thus happen.

Nevertheless, the precantions mentioned are good, and what of good there is in them I am convinced our friends, the British Acid makers, will at once recognise. So far as I recollect, the vital portions of these regulations are already observed in this country. 
Sitrie ncid: manufacture ind uses.

Nitric Acid: Mannfacture and Lises-It is not seldom the case in the chemical industries that whilst sinitary difficulties or dangers do not specially arise in comnection with the manufacture of a particular chemical, they may arise subsequently in the use of it. Nitric acid may be placed in this category.

The reason is not difficult to find. (1) The particular substance to be macle must be condenserl, restrained from escape in any form, for it has to be turned into money, and all skill and delicacies of appliance are, as it were, concentrated upon this olject, and so too a maximum of experience is gained. (2) Then, the modes of application by user's of the substance will mostly entirely differ from those of its preparation; and (3) in the application, the substance may be chemically decomposed, and then give rise to decomposition-products - which we designate by-products - that may be more noxious tham the original substance used.

After a good deal of thought on the subject I have come to the conclusion that it may be very hard both upon the manufacturers and the men, to use one term, such as "Noxious gases. rrunoed classi- or vapours" indiscriminately for all irrespirable gases ; for doxious gases. whilst the accidental inhalation of a certain amount of one gas or vapour, $A$, may produce symptoms which are transient, or which will at once serve as a direct evidence to the person affected, of its dangerous character, another gas or vapour, $B$, mily not do so, but induce slighter symutoms at first, which become aggravated later on, even when the arena of mischief has been abandoned for some time; whilst a third gas, $i$, may speedily induce narcotic symptoms, like the gats from the old sulphate of ammonia plant. Thus I should be inclined to separate such vapours and gases hygienically, and classify them as

Group 1.-Non-irritant irrespirable gases, such as nitrogen and carbonic acid.

Group 2.-Irritant noxious gases, such as hydrochloric acid, sulphurous acid, nitric acid, ammonia, chlorine, bromine and iodine vapours.

Group 3.-Insidious ivritant nuvious gases, such as nitrous acid (nitrons fumes).

GroUp 4.-Insidions non-irritant norious gaves, such as bisulphide of carbon, carbonic oxide, anrl sulphuretted hydrogen.

I should thus consider group 2 as the least dangerous, since giving immediate and adequate warning to the senses; whilst groups 3 and 4 are the most dangerous, as most immediately deceptive to the senses.

I shall say little about the nitric acid manufacture. In order to make a comfortable profit the manufacturer must 
condense the vapours, and not lose them to the detriment both of himself and his workmen. The older cylinder plant, as formerly worked, presented most danger of slight escapes in the preliminary mixing stage of the nitrate of soda and sulphuric; acid, but very little of such danger is presented in the perfect, apparatus now set up, and connected with excellent modern condensing arrangements. I lave recently visited a factory contivuous where an admirable continuous process is at work for making pritric neil nitric acid, and I should like to make as clear to you as mere words can do, what this apparatus and process are like, and the advantage of continuous working when possible. The apparatus and process are the rlevice of $\mathrm{Mr}$. Manning Prentice, of Stowmarket, and he kindly showed them to me in full operation, and answered all my questions. The older and well-known nitric acid cylinders require opening and closing, and charging with materials, and discharging of the crude bisulphate of sodil, and though with care, and with such admirable molern improvements, as, for example, the Guttmann apparatus with Lunge Rohrmaun condensor, or similar plant, most perfect condensation may be effected, yet a continuous process (always supposing equivalent economy), with continuous automatic feeding-in of materials (nitre and sulpluuric acid), continuous mechanical firing, with a constant and even evolution of acid vapours and acid, and continuous and steady out-flow of liquid residual bisulphate of soda, must always from the hygienic point of view be considered the most advantageous. The drawing annexed will illustrate the apparatus of Mr. Prentice, with its agitated charging fummel (a), delivering in a thin stream at $(b)$ the powdered nitre into a smaller lead fumel $(c)$, which leads direct into a mixing chamber, and thence into the still. Another fumel $(d)$ receives a constantly flowing and thin stream of sulphuric acid, which only meets the nitre insicle the small mixing chamber, and under cover of the still. The mixture constantly generating nitric acid vapours in the hot still, flows on in zig-zag fashion from one compartment of the still to the other, towards the fire, and so that mixture becomes continually hotter. As it reaches the fire-end of the apparatus it consequently contains continually less and less nitric acid, and the residue on emerging at $(s)$ is bisulphate of soda. From the first compartment, with its outlet $(e)$, a weaker nitric acid is obtained than that obtained at further outlets ( $f$ and $g$. ) These outlets are connected with separate condensing pipes, and furmish very constant acids; the less condensable fumes. pass to a small Gay Lussac coke tower, where they are absorbed by a down-flowing spray of strong sulphuric acid. The fire-. place is an ingenious one; such, that by a well regulated 
draught and mechanical stoking arrangement, as nearly as possible a constant heat is maintained. The whole apparatus

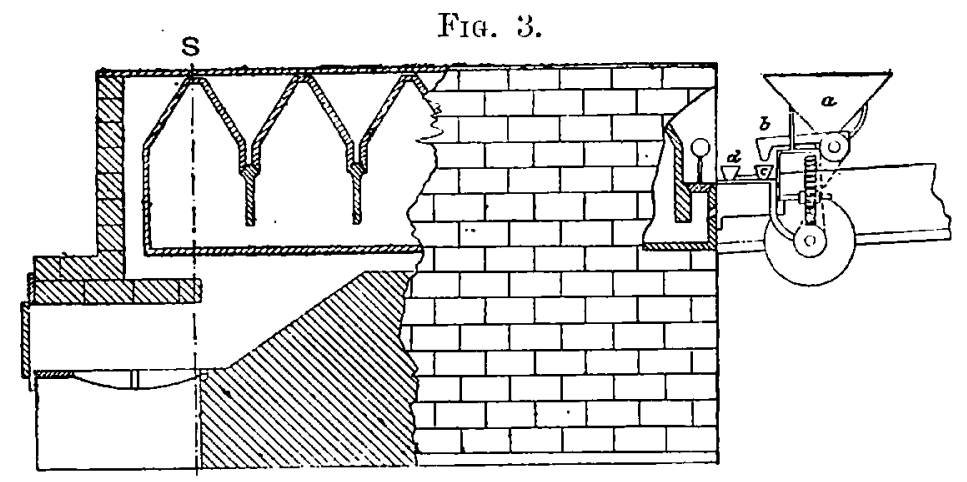

$\mathrm{s}$

EI.EYATION,
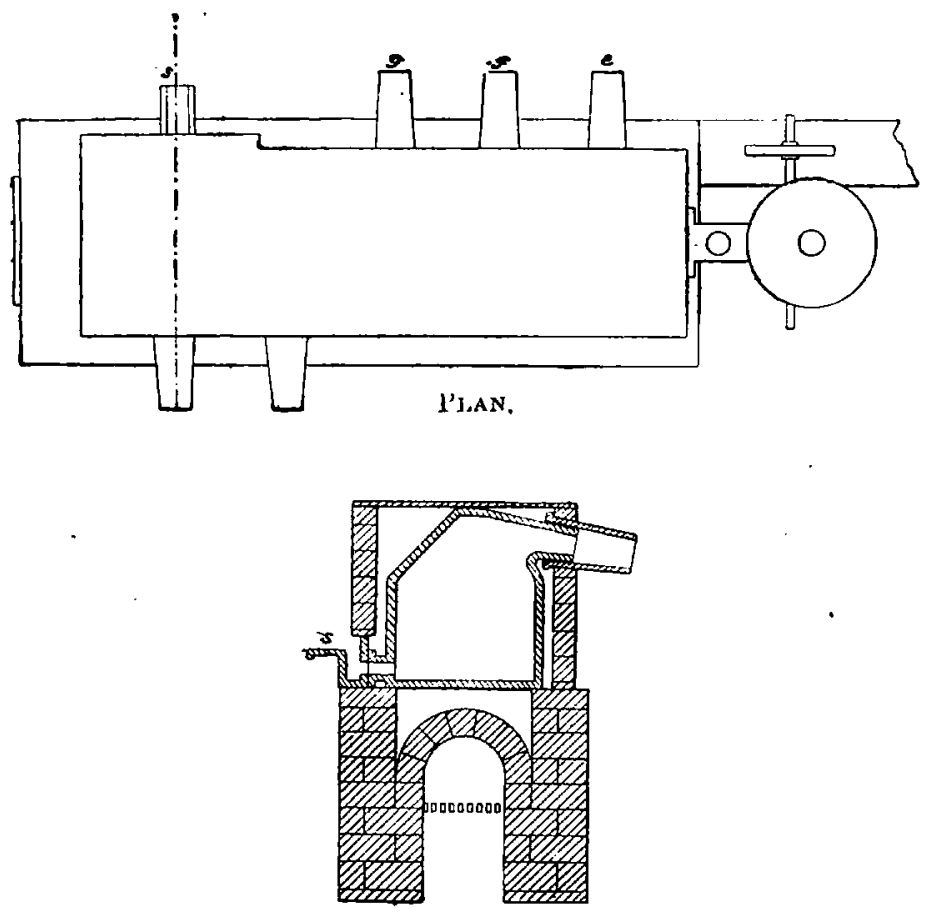

SECTION AT S S.

is under cover, and the little fume I could perceive, only came from the receiver, containing the manufactured acid, ready to be drawn off. 
In a nitric acid works, as my friend Dr. C. Otto Weber says, Nitric acid "the workpeople may be exposed to the vapours of nitric acid and nitrous acirl. To the former by escapes or accirlents, to the latter by accident. Nitric acid vapours form an irritant noxious gas, which gives immediate and full warning to the senses, and so I do not regard it under normal working conditions as dangerous, but nitrous acid is both iusidious and deleterious. It is a red gas, and its fumes are always abundantly srenerated when nitric acid comes in contact with organic substances through some accident. Take the usual case in a nitric acid works. A man breaks a glass carboy of nitric acid, Aecidents in niwhich escapes into the straw of the hamper in which it is tric ncid works packed." Volumes of nitrous fumes escape around. The work- trous fumes. man can casily beat a retreat, but not unfrequently, though against the rule, he may desire to hide the consequences of carelessness, and remain on the spot endeavouring to sweep up the spilled stuff. His lungs and life in such a case are in immediate peril, and I will try to explain how. The smell of the fumes is disagreeable rather than pungent. A slight choking sensation ensues on inspiring the mixed air and fumes, with a decided fit of dyspnœa if a little strong gas assail the nostrils. However, for a time the man gets over these symptoms by rumning away and breathing a little fresh air. After, say a quarter-of-an-hour, during which slight dyspnœa and tightness in the chest are felt, accompanied with nausea, new and alarming symptoms set in, of which I can speak from personal experience. These are as if a valve had been introduced into the throat, allowing tolerably free though spasmodic inspirations of air, but grarlually closing against expirations. This at length becomes very alarming, and if presence of mind be lost may learl to violent coughing, and then vomiting, accompanied by swelling of the body. Blood may even be vomited in such cases. Such accidents as these, I may say, place the masters in almost the same peril as the men. But in processes where nitric acid is used for oxidising purposes, unless special draught and condensing arrangements are fixed up, the men are undoubtedly exposed to much peril.

Of course the accident of breaking a nitric acid carboy may occur not only in a nitric acid works, but also in the other factories where such acid is conveyed. In such other factories Oxilution and this acid is mostly used for oxidations, and in these, nitrous nit:ating profumes are liberally disengaged. Examples of them are, the dengers. manufacture of the so-called " nitrate of iron liquor," of stannic chloride, in the oxidation of "white paste" (ferrous-ferrocyanide) into prussian blue, in the manufacture of all nitro compounds, \&c. A manufacturer informs me that in some small works at 
the present time only insufficient means exist for the removal and condensation of this dangerous gas, and that he recollects several cases in which inhalation of strong nitrous gas by workmen led immediately to fatal results. In two other cases the men succumbed on pneumonia supervening.

Nevertheless, let me say here that I have known many cases in which I greatly sympathise with the small manufacturer, who starts with the most humane intentions towards his employés, and necessarily must exert great economy to make a profit. He is of ten put to ridiculous and unnecessary expense by a certain class of inspectors of machinery and apparatus, who in very ignorance insist on vexatious and trivial, but costly, alterations of the plant and so squander the man's money fruitlessly, and leave him unable to effect for the time additions which might greatly improve the sanitary conditions of working for his men. The manufacturer would hail with delight a substitution of the visits of the inspector who is a scientific man, such as, e.g., the inspectors under the Alkali Act, but they are very averse to those of the ignorant and unsympathetic faddist, who merely worships his own petty authority.

Action of nitrons In liarge works where nitrous fumes are given off in more or fumes on voge- less continuous processes, the recovery of this gas, by means of
tation. a smaller or larger Gray Lussac Tower, is a matter of economic importance. Dr. C. Otto Weber informs me of a curious fact which he has observed. It is this. Although nitrous gas has such a deleterious action upon living organisms, plants and trees are remarkably indifferent to it. I may remind you too that in the case of hydrochloric acid vapours, the sensitiveness lies just in the inverse direction, minute quantities stripping the trees and killing plants, whilst animals with a little practice can breathe moderate quantities of it. We have thus an inverse sensitiveness to the two gases in plants and animals. Dr. W eber Inverseaction of tells me that he recollects that a "nitre shed" in Silesia (Verein hydrochloric cliemischer Fabriken) was surrounded with a remarkably fine
acisl. set of trees. In the shed mentioned the manufacture of nitrate of iron liquor was carried on, and frequently red clouds of nitrous fumes escaped and spread right amongst the trees, but only one of these, which almost overhung the short chimney through which the vapours passed, showed a few branchlets bare of leaves. The remainder of the tree, with all the others, exhibited not the slightest sign of injury, although this factory had been at work for sixty years.

Dr. Weber"says of the manufacture of nitric acid itself, "Nitric acid vapours very seldom escape into the atmosphere of the factory." He only linew of such an occurrence when one of the condensing tubes from the inuftle to the condensing plant 
had become fractured. He confirms my statement as to the perfection of the best modern plant. He says, "Such escapes very rarely occur now, owing to the very superior quality of the earthenware tubing for condensers now produced. But at one time such accidents were very common, and the heavy vaponrs of nitric acid quickly filling the room at once acted upon the respiratory organs of those present, and compelled them to beat a hasty retreat. The symptoms produced after an inhalation of the dilute vapours were quite similar to those produced by hydrochloric or sulphurous acid. Only when a workman exposes himself repeatedly to these vapours as, for example, in the attempt to draw the fire from the furnace after rupture of a tube, a severe affection of the respiratory organs can occur, no doubt as with hydrochloric acid and chlorine. At the present time, the stoke-holes of nitre furnaces are mostly so arranged as to be inaccessible to any vapours caused in the working of the process, either incidental to it or purely accidental." Dr. Weber adds, "As far as vapours are concerned in the nitric acid manufacture, I have no hesitation in saying that it is not so much nitric acid as nitrous acid fumes that have to be guarded against." However, in manipulating liquid nitric acid, es- Vasoline, to pro. pecially the new workmen, need to be informed of its instantly tect skin frow destructive action on the skin, burns and ulcers being formed. These wounds heal slowly and of ten cause much suffering if at all severe. It is greatly to be recommended as a safeguard against such burns and corrosions that a moderate supply of vaseline be allowed to the men, so that they may keep their hands well greased. Vaseline is inert to nitric acid and resistant to liquids, but the mistake should not be made of substituting animal or vegetable greases, which are attacked by this acid. Dr. Weber remembers that the attempt was once made in Austria to replace the fragile glass carboys, used for the conveyance of nitric acid, by strong earthenware jars. The dangers of breakage were thus greatly diminished and the railway companies willingly carried the acid packed in these vessels at reduced rates of freightage. However, the weight of the jars was so excessive in comparison to their capacity, that in spite of the reduced rates, the carriage in such stoneware proved too costly.

Hydrochloric Acid.-Hydrochloric acid is to-day the most Hydrociloric valuable product of the alkali manufacturer by the Leblanc process, though at one time it was a most troublesome byproduct. It represents the sole advantage at the present time which the Leblanc process possesses over the ammonia soda process, for it is the source of the valuable chlorine gas, which duly combined with lime and oxygen, gives bleaching powder 
or chloride of lime of commerce, used both for bleaching purposes and for disinfection. The first step of the Leblanc process consists in the treatment of common salt with sulphuric acid in cast-iron pans or pots comnected with long blinclfurnaces. Over the pots, dome-shaped arches are built surmounted with a short shaft soon turning at right angles in the direction of tall flag towers, packed with hard cokes, and down which water is kept trickling. From the short shaft over the salt-cake pot, a line of earthenware pipes proceeds and enters at the foot of the flag towers, first as a rule dipping into flag cooling cisterns. The gas from the furnace into which the half decomposed salt is pushed from the pot by the workman, is led into the towers by another line of pipes. In these towers a solution of the hydrochloric acid gas from the pots and furnaces is produced, that gas being very soluble in cold water. Thus, liquid hydrochloric acid is formed.

Gaseous hydrochloric acid is also produced in the Hargreaves' process, by passing sulphurous acid gas (sulphur clioxide) along with air over heated cakes of common salt, whereby these cakes are converted in situ into sodium sulphate, and hydrochloric acid gas escapes and passes on to the flag condensing towers to form liquid hydrochloric acid. The vapours of hydrochloric acid in anything approaching the concentrated form are corrosive and very irritating to the mucous surfaces and respiratory passages, more concentrated still they are quite irrespirable. In minute quantities in the air, though very destructive to vegetation, I must entirely dispute the statements so of ten made, that this gas (except in the presence of already existing lung (lisease), is injurious to health. In my own case I have invariably found as the principal effect, a wonclerful whetting of the appetite for food. Of course minute quantities of free hydrochloric acid occur in the gastric juice, but whether there is any comnection here I cannot say. Nevertheless, the fact remains.

Whilst resident in Manchester I used to visit with my classes in Chemical Technology, year by year, the Alkali Works of Widnes and its neighbourlood, and I observed invariably, after consulting the students who accompanied me, that the concensus of opinion was that the appetite was greatly increased. Pictures have also been drawn of the woes of the salt-cake men exposed to the vapours of hydrochloric acid, or as it is called, "salt-cake gas." These are mostly exceedingly overdrawn. For sore finger-tips and exposed parts, vaseline should be used, or rather, the parts should hare been protected with vaseline, which is inert to hydrochloric acid gas. W' hilst $I$ have observed no cases such as liave been pictured, I will tell you what I have seen, for years together, practised in the Lancashire and 
Cheshire Alkali Works: Women of the poorer classes, and even of the tradesman class, used to bring their infants troubled with whooping-cough, sometimes called "chin-cough" in the north, and beg to be allowed to carry them into the salt-cake sheds when the charges were being drawn. The inlalation of small quantities of hydrochloric gas was regarded as a specific against whooping-cough. If absolutely no result followed such administrations, or if the complaint became on the contrary aggravated, it is not likely such a practice would be continued from year to year; but I have been assured by parents that the beneficial results were most marked. Certain it is that women accompanied by small children, and of ten carrying infants in their arms, regularly bring their husbands' afternoon meals into the salt-cake and black ash sheds, and usually wait until the meals are over before returning, regardless of the vapours issuing from iron barrows full of freshly drawn salt-cake, or being filled with the material drawn from the furnace. Of course, they take care to keep to the off-side of acid vapour. The men themselves, when drawing the charges, are well bandaged around the mouth and neck. I like the German plan of using as a rough respirator a piece of damp sponge bound over the inouth, and I would recommend it for a trial.

I have already pointed out the sanitary advantages of con- Continuous hytinuous and almost automatic processes and apparatus for the processes. preparation of ammonia and nitric acid, and also that, as such improvements are made, the profit to the manufacturer and the comfort to the workmen increase pari passu. You will naturally ask if there are similar methods for making hydrochloric acid. I at once reply, Yes; certainly there are. There are the Tones \& Walsh and the Mactear revolving furnaces, in which salt is continually charged in through a lopper in one place, vitriol rum in through a pipe, and agitation caused by either revolving scrapers, or a revolving bed with fixed scrapers. Whilst salt-cake (sulphate of sodia) is continually discharged at its proper outlet, hydrochloric acid continually escapes and is drawn by the chimney draught to the flag towers for condensation, to form liquid hydrochloric acid. But the most beautiful and sanitary process to this end is that of Hargreaves, a fine plant for which, is at work a the factory of the Alkali Union, Ltd., known as the British Alkali Works, in Wirlnes, which is carried on on such a gigantic scale, and worked in such gradual detail, as to constitute a veritable continuous process, though in its details it is intermittent.

Let us now hear the results of Dr. Lehmann's physiological Plysiological experiments with hydrochloric acid gas. But here, at the out- action of hodroset, I must again quote Lehmann on Hirt's researches, and the 
figures he adduces for what he considers permissible quantities, or insignificant quantities of such gases as ammonia, sulphurous acid, and now hydrochloric acid. "Says Lehmann, "Woe to the workmen! who should be in a works in which such quantities of those gases contaminated the air." I lay stress on this matter-- firstly, because many of our medical men, physiologists and sanitarians, in this country have quoted Hirt, and seem to rely on his statements, mostly correct as to symptoms, but wrong as to figures; secondly, because I recognise a great possible wrong done to our manufacturers if those figures be relied on, in leading physiologists and others to pronouncements on the characters and sanitary properties of these gases in air, that may be extremely wide of the mark, and, thirdly, I could conceive it possible that, relying on those figures, sume might quote them as indicating that our Government Alkali Inspectors were umnecessarily severe and stringent in the low figures and high efficiency of condensation they insist upon. Lehmann finds the effect upon the lungs and respiratory apparatus in the case of hydrochloric acid gas, and of ammonia so similar, that he considers them togrether. So thoroughly has he made his experiments, that not content with torturing to death a number of cats and guinea-pigs, that he might post mortem examine their lungs, \&c., he subsequently operated upon himself and a friend. Of course he and his friend spared their own lives!

As Lelumaun was unwell, the experiments on himself were scarcely useful, but those with the friend, a strong man of thirty year's of age, are valuable. With air, in a close chamber, containing 0.05 per 1000 of hydrochloric acid gas, symptoms of irritation to the larynx and nostrils were experienced, causing continual sneezing; instinctively breathing was effected through the nostrils alone, and by means of small and superficial draughts of the acidified air. Gradually, a certain degree of smarting at the chest was felt, and some hoarseness; also there arose a certain choking sensation in the throat. No acid taste could be perceived, and no smarting of the eyes. The man, a stranger to such fumes, declared that to work in such an airspace would be intolerable, and begged, after twelve minutes, to be let out.

After more experiments on himself and others, Dr. Lehmann states that he thoroughly believes that people of sound lungs, after a certain degree of practice, may become accustomed to breathing small quantities of hydrochloric acid, even stronger doses than that mentioned above, without any too great diffculty or danger; but that the limits for any considerable stay in such atmospheres ought to be drawn at 0.1 as minimum or 
$0.2 \%$ at the very outside as a maximum. Hirt specifies 5 to $11 \% \%$ i.e., 50 times as much as for a small dose, which, I confess, I should like to see him try for five minutes!

The appearance of the lungs of the animals experimented on, that had inhaled considerable quantities of ammonia and hydrochloric acid gas, Lehmann describes as almost exactly resembling those of such animals as horses and dogs that have been found in stables which have taken fire accidently, the animals having been choked to death with smoke and empyreumatic vapours.

\section{Chlorine Gas.}

This gas is prepared for the manufacture of bleaching pow- Chloring gas. der (chloride of lime) or for the manufacture of bleaching liquor, which might be termed bleaching powder solution, by subjecting hydrochloric acid to the action of such an oxidising agrent as manganese peroxide, or as in the Deacon process to the action of the oxygen of the air under special conditions. The hydrogen of the hydrochloric acid is thus separated to form water whilst chlorine remains as a greenish yellow heavy gas of peculiar odour which is greedily absorbed by slaked lime, milk of lime, or alkaline solutions. On the large scale, hychochloric acid is run into stills made of flag-stone containing manganese peroxide, or if manganese mud be employed as recovered by the Welclon process, this is run gradually into hydrochloric acid contained in these stills, which are suitably heated with steam. The chlorine gas generated, passes through short removable arms of stoneware or lead to a gas-main which conveys the gas to leaden chambers resembling small vitriol chambers, sometimes set on the ground, sometimes mounted on pillars. In the latter case the finished bleaching powder can be more safely, quickly and comfortably shovelled through suitable openings in the floor into the powder casks placed below the chamber's. These chambers are supplied with windows, one on each side, and by looking through from one to the other, little more than traces of clllorine can be distinguished by the colour communicated to such a thickness of air. Chlorine is an irritant noxious gas, and its odour is very characteristic. It is more choking than hydrochloric acid gas, and more difficult to get rid of from the respiratory apparatus when inhaled, for it is not so soluble in aqueous liquids, and hence, in the salivatic and mucous discharges the flow of which it excites. Nevertheless it is a gas to some extent soluble in water, and the solution in contact with air and light, rapidly becomes changed into one of hyclrochloric acid. So great is the affinity of chlorine gas for fresh slaked lime, arranged as it is in ridges resembling a ploughed field, so 
as to give increased surface, that advantage is taken of this fact, to clear a finished chamber of residual gas, by simply connecting it by a light leaden movable pipe with a neighbouring chamber containing fresh lime, and leaving an air-hole or opening in the finished chamber. The attraction for the chlorine by the fresh lime soon sets up a draught, and fresh air is drawn in at the

eaching wier.

Irances in nitation of the eaching powir industry.

Icoholism, an betacle to nproved saniition. openings of the finished chamber and thus it becomes ventilated.

Before 1886 a bleaching-powder man going to a chamber, and judging as to the complete absorption of the clilorine gas by a mere rule-of-thmunb process, wonld proceed to open it, not unfrequently to find the gas only partially absorbed, sometimes still with a content of 100 grains of chlorine per cub. ft.; of ten with 15 or 18 grains of chlorine. The result of finding such a choking atmosphere was a rapicl retreat for fresh air. Such rule-of-thumb or guess-work process was often due to negligence in keeping the glass winclows or "sights" clean. Now, i.e. since 18sti, these errors are prevented (except of conrse in cases of sheer wilfulness) by a rule made obligatory by the General Inspector in 1886-87, viz, that no doors shall be opened until, hy a suitable test, the internal atmosphere is found to contain something below 5 grains of chlorine per cull. ft. The amount $I$ understand that is usually kept to is 1 grain per cubic foot. A simple automatic test is provided for this purpose. To show how willing the alkali manufacturers are to meet the Inspector in any devices for the sake of the health and comfort of the workers, let me mention that Mr. Brock (the Chairman of the Alkali Union) himself introduced an additional rule and a process for more quickly removing the chlorine, viz., by a final diffusion of lime-clust through the chamber space. As it settles, this dust absorbs the residual chlorine gas, and a harmless atmosplere remains, which the packer can enter with safety and comfort.

It is a singular thing that the profession of bleaching-powder packing and chlorine-still working, seems to be almost entirely in the hanils of Irish workmen, and this perhaps accomts for the further suggestive fact, that the one clesire of these men, with but few exceptions, is to find any excuse for claiming monetary assistance for the libations, "the dlerop of Irish whuskey," which form their invariable specific for all "gassing" ailments. No helmets, waterproof clothing, or respirators would last a week, if worn at all, in the majority of cases, if it were known that the whiskey money must be stopped. Bright exceptions to this general rule are to be found, but they are comparatively scarce. The paclers prefer to bandage their legs well with folds of cheap cotton and brown paper, and also their necks, moutlss, and nostrils with cotton folds, before enter- 
ing the chambers. This it is quite as necessary to do on account of the dust of the powder as on account of chlorine gas. Of course the eyes are protected with large goggles, the lime-dust, nevertheless, sets up conjunctivitis from time to time. The preparation and sieving, as woll as spreading of the lime in the chambers, is a trying piece of work; but the painfulness of it might be much reduced if the men would only accept the helps and defences that are offered to them, and especially abstain from whiskey drinking. The skin is generally greased by the men who enter the chambers. Vaseline ought to be used here again. I would also recommend the use of mouth sponges covering both mouth and nostrils under a less heavy cotton bandaging. The sponges are readily removed, and easily washed and wrung out from time to time. The bandages are often worn until both dirty and very acid, and when pressed against the tecth are likely to set up corrosion of them.

Lehmann says that there is not the least doubt that Dr. Lehmann gradually certain individuals amongst the workmen can get on acquiren accustomed to inhalation of moderate quantities of dilute chlorine ${ }^{\text {aguinst chlorine }}$ gas, but there are some individuals too who cannot acquire this habitude. 'The work's proprietor himself through repeated visits into the factory acquires some of this faculty. One manufacturer of bleaching powder told Lehmann that some workmen will occupy spaces for a day together which he himself would have to quit af ter only ten minutes cluration. Christison, speaking of blench works, states that the chief result of habitual exposure in the chlorinated atmosphere, is that the men get acid in the stomach and other stomach disorders, which thev try to remove by taking chalk. These men never become stout, and if stout at first as other men are soon reduced to leanness, Cluristison fincls that many of these men grow old, and he sees no reason for considering the work unlealthy.

Dr. Frank has also noticed the tendency to leanness in Dr. Frank opworkmen exposed to bromine vapours, which are more trying posed to whiskes than chlorine. He recommends plenty of fat foorl, and the utmost abstinence from spirits.

This abstinence from spirits of course applies similarly in the case of chlorine, and yet we find the workmen insist upon drinking it as a remedy! I liave known a man "gassed" with Incompntioility chlorine to take hot whiskey and water, and subsequently to of whisley toddy. become for the time stark mad, six or seven men being required to hold him. The statement that workmen exposed to chlorine atmospheres are predisposed to phthisis thereby, is contradicted by recent authorities. I myself have drunk small quantities of weak sulphuweak sulphuretted hydrogen water when gassed with chlorine, retted bydrogen and with immediate relief. Renk, who studied the condition of dote. 
the workmen in paper mills, where rag bleaching with chlorine takes place, could trace no injurious action of the chlorine at all. In the Bleachworks of Freiburg in Silesia, Hirt noticed the low rate of mortality of 1.25 per cent., and the high average longevity of from 56 to 58 years. Statements have been made as to the terribly unhealthy condition of Widnes, the great Lancashire alkali centre; my experience was dead against that, and I have here the death-rate of this town compared with those of larger towns, such as Warrington, Blackburn, Liverpool, Preston, and Manchester, showing that it is considerably below all these; indeed, the statistics I have here are those specially prepared for the Labour Commission, and they contain some very remarkable testimonies of workmen who have grown old in the alkali manufacture, and have also grown hale and hearty, because moral, steady, and temperate.

Diagram showing average death-rate of Widnes compared with other large towns, for the ten year's, 1881-1890.

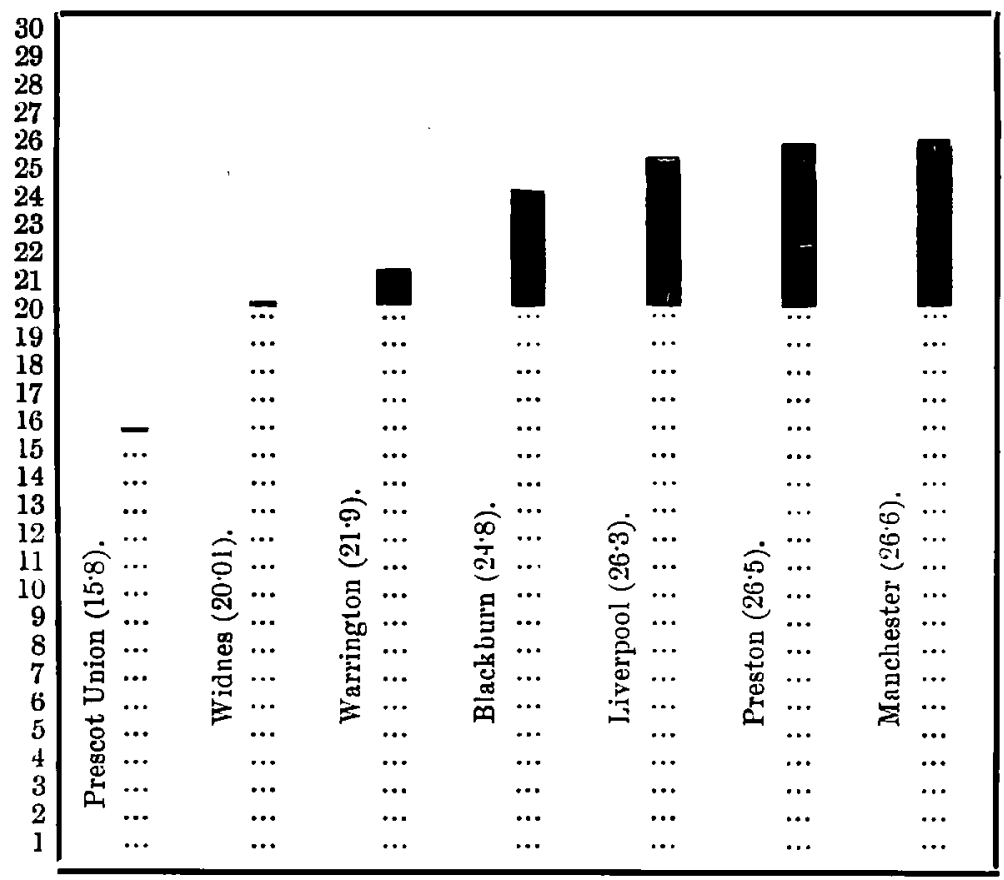

I now append the testimonies of several bleach packers and a "burner" man, employed by the Alkali Union, which speak for themselves. 
John Darlington was prepared to declare that:-He is a Testimonies saltcake man at the Weston Alkali works. His age is 45 years. $\mathrm{He}$ has been employed at this work for 26 years. His general state of health is good. He has never known any men suffer in health in consequence of "gas." His hours of labour are 50 hours one week and 84 hours the other. The men, as a rule, are temperate. He, himself, was teetotal for five years, and now only takes liquor occasionally. 'The men, on the whole, are not improvident. He does not believe that the teeth of the men in the saltcake department are affected by the "gas," but that in cases where men suffer in this respect, it is a result of using dirty cloths in their mouths. The men have ample time for meals, and have half an hour to rest every two hours.

Thomas Percival was prepared to declare that:- He is a burner man at Messrs. Wigg Bros.' Works, Runcorn. His age is 58 years. He has worked (pyrites) burner's for 17 years, and has been employed in a chemical works 44 years. $\mathrm{He}$ has enjoyed general good health. He does not consider that burner men suffer in health as a consequence of the conditions of labour. Although the hours on duty are long, the work is light, and only occupies about half the time. He has never seen any workman rendered insensible from the effects of gas.

Thomas Barnes was prepared to declare that:--He is a bleaching-powder packer at the Weston Alkali Works. His age is 53 years. He lias been employed in packing "bleach" for 34 years. His general state of health is good, and he has only lost one day's work during the past 18 years through illness, which was in no way connected with the nature of his employment. He las never seen anyone insensible from the effects of chlorine gas. He does not believe that the work affects his health, but considers it a healthy employment. He does not consider it necessary to drink rum to enable him to perform his duties, but believes that he can work much better without intoxicants of any kind, which he thinks are injurious. He works from five to six hours per day.

Jons MCLeOD is prepared to declare that:- $\mathrm{He}$ is a "bleach" packer at Messrs. N. Mathieson \& Co.'s Works, Widnes. He is 49 years old. He has been a bleach packer for 30 years, and has been employed in chemical works altogether about 33 years. He has never lost any time through illness in connection with his work, and has had very good health. He has never been rendered insensible from the effects of chlorine gas, nor has he ever seen anyone else insensible from 
this cause. He has been practically teetotal for the last 13 years, and does not consider it at all necessary to take intoxicants to enable him to perform his work. He thinks the ordinary flannel muzzle the best means to adopt in packing a chamber. He has never found it necessary to complain of any of the conditions under which he is obliged to work. He works about 36 hours per week.

James Campbell is prepared to declare that:-He is a bleaching-powder packer at the Widnes Alkali Co.'s Worlss. $\mathrm{He}$ is 36 years old. He has been packing 16 years, and has been employed in chemical work about 20 years. His health has been on the whole very good. Has never seen or known any man to be rendered insensible from the effects of chlorine gas. Does not consider it necessary to take stimuliunts to carry on his work. Does not consider men employed in chemical works exceptionally intemperate. He does not consider the "Denayrouse" apparatus suitable for bleach packing. He has heard of it being used by a man at Muspratt's Works, but it was found to be impracticable. He would not be disposed to use it for this work himself, preferring to use the ordinary flamnel muzzle. Has no complaints whatever to make regarding the conditions of his work.

The great bane of the alkili and bleaching powder worker is his usual partiality for spirits as a beverage. I have observed, and believe it to be generally true, that when syphilitic or scrof ulous taint exists, the drinking of spirits brings such taint to the surface, and then very slight external influences suffice to bring forth eruptive diseases.

Strong cerebral action of Cl. and Br.

Pathologic action of Halogens, a periodic function.
It may be well to remember that both with strong chlorine and bromine, a sudden exposure may result in a sudden lapse into uncousciousness with falling to the ground.

Chlorine does not attack the cornea and eyes, nearly so quickly or painfully as bromine does. With the latter vapours, spasms of the eyelids of a very painful kind soon set in, the lids becoming tightly and spasmodically closed. The attack on the skin and mucous membrane, as Lehmann shows, is rapid with bromine but scarcely noticeable with chlorine, and of course it is still more rapid with iodine, and here we observe as in many of the other properties of the three halogens, this curious increase or diminution of affinity as the atomic weights rise or fall. Bromine acts with special vigour on the hair or fur of animals. Lehmann determined as nearly as possible the amounts of chlorine and bromine respectively, necessary to kill a small animal like a guinea pig. On calculating out the results, I find that the 
average numbers representing the respective weights of chlorine and bromine, are as nearly as possible those bearing a ratio to each other of $80: 35 \cdot 5$, i.e., inversely as the atomic weights of these halogens. Hence the power destructive of life in these two substances, is in the direct ratio of the atomic weights. Probably iodine may be safely included in this law.

Lehmann considers that an atmosphere containing 1 to 2 millionths $(0.001-0.002 \%)$ of chlorine or bromine is quite uninjurious and very little troublesome, whilst $0.003-0.004 \%$ 3 to 4 millionths, are very irritating and cannot long be enclured advisably. $0.005 \%$ should be perhaps regarded as the maximum amount that can be safely tolerated for a brief period. Larger proportions than the above, for periods of a few hours, can only be inhaled with danger of injury.

In his experiments on small animals Lehmann could detect no action on the heart that could be taken into account, also the action on the eyes, mouth and mucous membrane of the nostrils was comparatively insignificant, but bromine distinguishes itself greatly over chlorine in its action on the hair and epithelium of the stomach, whilst the kidneys, liver and other abdominal organs were not much affected in the case of either gas. The Noteworthy discurious distinction between the action of the halogens in vapour- tinction between form and that of their hydrogen compounds, hydrochloric and gens and their hydrobromic acids, was observed to be, that the halogens exhibit a much stronger cerebral action, if indeed any cerebral action at all in the case of the hydrogen acids can be spoken of. It is interesting to note that Lehmann after his experiments in a closed chamber, went to a German paper works and examined the bleaching departments and its conditions. He found that the average amount of chlorine in the vicinity of the soming vats during the process varied between $0.00 \mathrm{~L}-0.004 \%$ of chlorine, i.e., 1 to 4 millionths. He observed that the workman at the period of strongest gas stood in the cloorway to get as much fresh air as possible. This individual told Lehmanu that at first the gas gave him a severe catarrh with expectoration of much mucous, \&c., but that gradually he had grown accustomed to the gas, and ceased to become affected. He seemed to be a thoroughly healthy man.

I quite agree with Lehmann as to the possibility of becoming Acquired skill hardened to the action of small quantities of the pungent gases in breathing in mentioned, which are not what I have described as insidious, but atmospheren. I would ascribe a great deal of this so-called "hardening" to a kind of acquired skill gradually tanght by instinct, and which cannot be adecuately described. Nevertheless, I believe it can only be acquired by persons with sound lungs. I myself have often breathed with a fair degree of comfort in atinospheres 
containing hydrochloric acid or chlorine, in which I lave observed a novice almost choking. The kind of acquired respiration necessary, I can only describe as one in which a larger. number than usual of cautious but superficial (i.e., not deep) inhalations are taken, not through the mouth, but through the nostrils. With one or two deep breaths through the mouth the novice is placed "hors de combat!"

\section{InJURIES CaUSED by CONTACT with Gases and Liquids- Prevention and Treatment, \&C.}

I notice in my reading of the great German organ of the Chemical Industries, "Die Chemische Industrie," that the large number of accidents which occur to workmen appear to arise through various intricacies of the apparatus in German factories, and through what seems to me as I read, the nervous desire to show an over-hasty obedience, combined with a lack of personal observation and independent judgment and selfreliance. I put a great deal of this down to the effect of hard military discipline, and say without hesitation that a good sturcly Irishman would know how to protect himself a great deal better, and yet do his work. If we add to the disability named, the greater complexity of German apparatus, already mentioned, and the increased minutia, I do not wonder at the records of so many injuries cansed by men falling down ladders here with jugs of vitriol iu their hands, and turning wrong taps on there, and in violent haste to set things right, getting hold of other wrong taps, and injuring the face and eyes with something yet more noxious. I trace these accidents in great measure directly to stringent militaryisn, which has converted men into so much unself-reliant machinery, and I say, let not readers of the journal quoted think that British workmen thus suffer, because I can assure you it is not the case, nor do the manufacturers here need such an excess of bye-laws, restrictions, and precautions. We have our own peculiar faults, but we are not over-drilled!

However, we shall do well to hear of the means of preventing injury, remedies, etc., compiled by the German firm, K. Oehler \& Cu., Offenbach-a-M., on "Corrosion and Burning with Lnorganic Acids and their Treatment."

I should like, on perhaps another occasion, to give the text of this interesting and valuable pamphlet, but will now content myself with a summary.

1. In the case of any burn with strong acids, the chief measure of importance is as quickly ars possible to dilute and 
remove the acid from the part affected by copious affusions of water.

2. The neutralisation of any remaining acid by means of weal- solutions of alkaline carbonates, is desirable.

3. A corrosion is simply a burn, and must be treated as a burn : air-tight banclage, with goulard water compression.

4. With extensive burns, it is highly desirable to avoid, in every possible way, a loss of heat or chill in the subject under treatment, by administration of a warm bath; warm leadwater compressions, \&c. Nevertheless, it is perfectly evident that the quickest possible dilution, and washing away of all acid, must be regarded as the first duty to the man.

In the case of burns and scalds, we in England are almost invariably supplied with a stuck of the good old linseed oil and lime water, and this is highly spoken of too in Germany as a safe palliative in unprofessional hands. But a better remedy still is one devised by the large German firm, Bayer \& Co., of Elberfield, for use for their workpeople in case of burns and scalds. This consists of an organic preparation called "Aristol," an Iodo-thymol compound, which is used in the form of a 10 per cent. lanoline or vaseline salve, or even in the form of powder, to be laid upon the wound. A subnitrate of bismuth, as prepared by a South German firm, is also very warmly recommended for burns. Either of these preparations much diminishes the pain of the wounds.

In all places where dangerous work is carried on likely to bring about burns or scalds should accidents occur, it is recommended that plentiful supplies of water should be close at hand.

The use of suitable spectacles is strongly recommended by Use of specLehmann and by the various authorities, and great fault is found with some spectacles that are already in use. It also appears, that like their English brothers, many of the German workmen will not wear these spectacles if they can help it, or even respirators. The kind of spectacles most recommended are those devised by Stroof, and patented by lim. These have means for the circulation of air through them, and thus the eyes are kept cool.

Another kind of spectacles obtained the first prize recently from the Association des industriels de France contre les Accidents $d u$ Travail. This prize was won by Simmelbander, of Montigny, near Metz. It is made with trapezoidal glasses (J. Soc. Arts, Aug., 1893, 876), surrounded by wire gauze; does not heat the eyes, and is specially useful in cases where corrosive liquids may be thrown about in spray as the result of accident or otherwise. 
tective mask. Dr. Lehmann most strongly recommenrled the use by workmen and others of a protective mask, invented by Herr Pitzner, Engineer in Chief of the Seydelmayer Brewery in Munich. Lehmann has worn this mask himself in all linds of noxious atmospheres and thoroughly experimented upon it. It appears actually to be a kind of light helmet marle of soft indiarubber, which loosely encloses both hearl and neck, whilst the eyes are protected by two large circular glasses. In the neighbourhood of the mouth is a strong indiarubber tube passing out into the fresh air and connected with a powerful bellows. Whilst the workman operates in the noxious atmosphere, a strong stream of fresh air is blown to his mouth, the loose soft rubber around the head and neck expanding or contracting as the excess of air increases or diminishes. Also any openings through the loose fastening of the helmet are of no detriment, the escaping air preventing return of obnoxious gas. Lehmann's exhaustive experiments with the mask show how effective it is, at all events, for a man not attempting any hard work in it.

rmerly used kious respira's in Germany

jinfecting man beings it chlorine 1 bromine.

It appears from Lehmamn that, at one time in Germany, sponges moistened with aniline were recommended as respirators for men working in atmospheres containing chlorine, and these he properly condemns, since aniline vapours are more noxious than chlorine itself ! It may be interesting to refer to a paragraph written by Lehmann on the attempts that have been made to disinfect human beings in cases of serious epidemics, with chlorine and bromine vapours. $\mathrm{He}$ points out that the experiments of Fischer, Proskauer, and others, demonstrate the futility of any sucl method of disinfection, since it was found that for the destruction of the organisms it was mecessary that the moist atmosphere of the sterilizing chamber should contain 3 per 1000 of chlorine, or $2 \cdot 1$ per 1000 of bromine, and the exposure should continue for three hours, or there might be used an atmosphere containing 0.4 per 1000 chlorine or 0.3 per 1000 bromine, with a twenty-four hour's' exposure. Lehmann very pertinently, and somewhat humorously, says: "The microorganisms would, under the above conditions, be very effectively slain, but so also would the patients!" Besides many pathogenic bacteria can easily withstand the action of an atmosphere containing as much as 4 per cent. of chlorine for an hour togrether.

Before concluding, I should like to refer to one or two facts of great interest:-

emical work- The first is the predisposition, as already mentioned, to
n with in with
ofulous taint. eruptive complaints shown by a certain class of workpeople of scrofulous or syphilitic taint. Dr. Arlidge in his work mentions the occurrence of skin eruptions in the case of bleaching 
powder workers, through the action of the chlorine. Such eruptions I have never observed, but I can say this, that men who inherit scrofulous taint, are quite liable to such eruptions in chemical works at the slightest provocation. Such persons, as well as those with lung diseases, or even with heart disease, should, if possible, choose other work to clo.

The second is the curious fact that in some chemical works in which a variety of products is manufactured, it is found that the influence of the conditions of one department acts as an antidote to those of another in which some injury is contracted, and accordingly the men are changed about from one place to another.

In conclusion, and in view of some lard things that have are our alkali been said of the chemical manufacturers in their relations to $\begin{gathered}\text { and neid } \\ \text { manufacturers }\end{gathered}$ their workmen, I should like to mention two facts which have humane mnsters recently come to my notice, and after mentioning them I am content to leave it to the public verdict, whether the chemical manufacturer, and more especially in this comnection, the alkali maker, does not possess his share of humanity.

The first fact is that at a recent meeting of the Liverpool Section of the Society of Chemical Industry, two of the chief magnates of the Alkali Union set forth the advantages and spoke entirely in favour of, an eight hours day for the alkali men. The second is what $I$ call a beautiful testimony to the same good feeling. During the late coal famine, when many of the Alkali works were brought to a standstill, especially in and around St. Helens, the principal officials of the United Allkali Co. started a relief fund for their out-of-work hands.

A strong committee was formed, with a secretary and treasurer, and this committee had received promises of weekly contributions amounting to $£ 150$. It was estimated that these sums would provide $2 \mathrm{~s}$. $6 \mathrm{~d}$. per week for each single man, and 5s. for each of the married men, thrown out of work through the scarcity of fuel. The first distribution of relief was made on Nov. 20th, when 742 workmen, representing 2,500 souls, participated. But numerous outside applicants for relief presented themselves, and an appeal was macle for public support.

Hence, the hearts of this Alkali Union Committee were good for their own men, and large enough to take in the woes and distress of a famine stricken population outside them. 